\title{
Environmental problems - a transnational solution supporting co- operation of all relevant social forces
}

Josef Burgard* *

Siemens Telekooperationszentrum am DFKI

Stuhlsatzenhausweg 3, 66123 Saarbrücken, Germany, tel.: +49

6819375 110, fax: +496819375188 ,

e-mail: josef.burgard@stz.dfki.uni-sb.de

\section{Rainer Güttler}

Hochschule für Technik und Wirtschaft

Goebenstr. 40, 66117 Saarbrücken, Germany, tel.:+49 681

5867 238, fax:+49 6815867 122,

e-mail: guettler@htw.uni-sb.de

\begin{abstract}
TEMSIS - Transnational Environmental Management Support and Information System is intended to be a tool for transnational co-operation between the communities in the German-French urban agglomeration, Moselle-Est / Stadtverband Saarbrücken. Its main objective is to integrate existing information platforms of local environmental authorities in Germany and France, to support information exchange and thus strengthen the co-operation which is necessary to solve common problems. One main idea is to inform the public very early if
\end{abstract}

"Co-authors and project participants are:

Dr. Jean Schweitzer, Siemens Telekooperationszentrum am DFKI

Ralf Denzer, HTW, Germany

Bernd Hoffmann and Uwe Kleffner, Stadtverband Saarbrücken, Germany

Rene Momper, Mairie de Sarreguemines France

Ralph Pfannkuche, Siemens Nixdorf Informationsystems, Germany

Heinrich Humer, Gerald Schimak Austrian Research Centre Seibersdorf, Austria

Christian Marchionini, ARGOPOL, France 
planning activities start, to create intensive discussions among all involved participants and thus to make decisions transparent.

The project is related to the Telematics Applications Programme of the European Community.

\section{Keywords}

Distributed database, Telecooperation, multipoint video conferencing, T.120, Environmental information, bilingual text generation, Metainformation, Geographical Information System, workflow integration, Administrative Kiosk, Public Kiosk, local authorities, European Community

\section{INTRODUCTION}

The demonstration region for the TEMSIS project is the Saar Rosselle Region which is constituted by the transnational urban agglomeration of Saarbrücken and Moselle Est. For the past 25 years radical changes to the regions industrial structure have been taking place. This industrial past has left these regions with a number of serious environmental problems; the communities on both sides of the border have been meeting for a number of years to discuss their common problems and development. Any decisions concerning new industrial development will have environmental impacts as well as social impacts on the region as a whole without regards to the national frontier. To prepare the decision by local authorities, usually an environmental impact statement will be necessary, and citizens have to be informed about the various projects and their impacts.

\section{OBJECTIVES}

The main objective of the TEMSIS project is the development of a so-called "demonstrator" as a complex distributed support and information system providing users with access to a well defined reservoir of environmental information and to interpersonal desktop collaboration services.

The use of this distributed system will be done by two types of infokiosks, an "administrative version" and a "public version". These infokiosks offer the users an easy access to the information gathered in the distributed system "hiding" all network activities to the users. Decision making needs in addition cooperation of different authorities and experts to get reliable information. Especially the different transnational law and interpretations have to be taken in account. Many discussions among the expert groups will be necessary to get a common understanding. 
Communities and regional/local authorities responsible for the execution of legal environmental regulation need very strong detailed information about the state and the change of environmental parameters. In order to have an information basis to make reliable decisions the data must be accurate, up-to-date, sufficient and understandable.

This data is normally distributed to many organisations, it must be requested from there and transformed into a format allowing comparable transnational analysis. The traditional way of doing this is very slow and expensive and cannot be realised in every project. Within TEMSIS the access to an extract of data sources should be enhanced. Discussions within the user groups results in three main aspects:

- It has to provide information about resource consumption. This includes the consumption of open spaces, of drinking water and energy.

- Second, an environmental information system has to offer information about the degree of pollution of different kinds of resources. Monitoring of installations and plants is also part of this topic.

- Third, the system has to provide impact assessment. This means that it has to inform about different topics in a kind of survey of the environmental situation. A view as wide-ranged as possible is more useful for this application than a profound view of only a few topics.

The last point is completely conform with the environmental information act, 7th June 1990. According this European citizen have the right of information on environmental data.

Based on comparable information cooperation between transnational administrations is possible. The main working areas for political and administrative collaboration are:

- the management of environmental crisis and alarming situations across national border, which is out of the scope of TEMSIS

- the exchange of environmental data based on monitoring of the environment,

- collaboration in environmental decision making, e.g. if new planning activities arise.

\section{TOOLS}

The different systems like Meta information system, Geographical Information System(GIS) and Telecooperation system are usually independent tools which have to be customised to the special problem. This requires adaptations and interfaces to communicate and exchange data. Following the most important components are presented. 


\subsection{Integration of Environmental Information}

Integration of distributed, interdisciplinary data is difficult for various reasons which can be seen for example from the Austrian Ozone Network (Schimak, 1994), where the 10 existing air pollution measurement networks operated by the Austrian provinces had to be combined. The main problems integrating such systems are (Denzer, 1995)

- the systems are heterogeneous

- the systems are operated autonomously by different authorities

- the systems change dynamically

To overcome these integration problems, sophisticated distributed software systems on an advanced communication infrastructure are needed. Metainformation describing the syntax (storage types, structures) as well as the semantics (the actual meaning of items as well as aggregates of information) of the data is a key aspect for the solutions.

The different systems to be integrated in the demonstrator e.g. were not designed for the purpose to interact with other systems. To achieve this we want to let the existing systems as they stand and cover the functionality needed for the integration in the distributed system by developments of additional subsystems. An information exchange system which we call information service has to be developed based on a distributed metainformation system. To achieve this every node of the network has to offer a local metainformation server which in most cases has to be developed within the TEMSIS project.

\subsection{Geographical Information System}

Geographical Information Systems (GIS) will be used in local, regional, national and international areas to analyse and present environmental data and to support decision making. SNI is the leading company in the GIS technology for environmental management systems. New concepts for Multimedia GIS Systems will be developed and adapted to the special requirements of Telecooperation and meta information systems. Systems like 'Sicad' with full GIS functionalities are available on workstations with Unix operating systems. To present environmental data you don't need such complex functions, simple low cost Viewer system with some GIS functions are now available on PCs.

\subsection{Telecooperation}

Telecooperation systems support distributed teams in a very efficient way directly at their working place, geographical distances are no more relevant. The computers are connected to a global network and the applications used are moving towards co-operative working environments. There is a lot of potential computer 
support because co-operative activities are manifold and most of the information systems are computer based (Burgard, 1993)

Within the TEMSIS project Telecooperation systems are used in the environmental area for the first time. The co-operation of the transnational communities will be supported by videoconferences and application sharing system. That means that during the planning of a new project like new housing or industrial areas or new infrastructure like roads or railways the local and regional authorities can discuss and look at a common environmental map. They are able to make changes at once which will be visible to all participants of the Telecooperation session. A complete conference scenario including invitation of the conference team and the management of the shared application will be available Multipoint video conferences will be supported (Schmidt 1994).

Problems concerning conferences are the preparation, the storage of the state of a conference and the restart at this point. Normally conference sessions are embedded in a flow of business processes. Workflow systems are supporting these flows which are mostly very strict actions. Using Telecooperation systems together with workflow management systems you can make the business more flexible (Schweitzer, 1996). Together with some tools to store and to restart sessions at a definite state you can manage complex business cases.

\section{SYSTEM ARCHITECTURE}

\subsection{End User Systems}

The presentation component distinguished into type "A" and type "P" infokiosk. Within the P-Kiosk we actually investigate the possibilities of world wide web in conjunction with new methods like Java applets programming. The „A-kiosk“ will comprise a desktop conferencing system supported by additional Telecooperation functionalities mentioned in chapter 4 . The system is based on a low cost Hardware component consisting of video and audio components including an ISDN adapter board. It is called I-View and developed by Siemens. Special implementations will allow moderated multipoint Telecooperation sessions using a central Multipoint Conference Unit (MCU) and a Telecooperation server . The environmental data, especially geo-referenced data and some factual data will be presented by a GIS-viewer, called WinCAT, from SNI.

\subsection{System Server}

The metainformation service navigates the user request to the relevant network resource and database. The service provides a component which knows about the network it should use and an other component which has information how and where it can access data in which database. 
The Temsis database itself may cache temporarily information, store the updated information of the data bases and handle layer-files storage. But mainly it will keep the metadata.

The bilingual text generation service transfers the requested data into the demanded language taken into account that there are different interpretations in Germany and France.

Finally the TEMSIS Web server will generate web pages to present the data. It can be accessed either by the Internet or a direct ISDN connection for special public stations.

\subsection{The environmental databases}

Data will come form different environmental databases. It is planned to integrate the German and French air quality databases of their air quality measurement systems in the Saar Rosselle Region to provide continuous data.

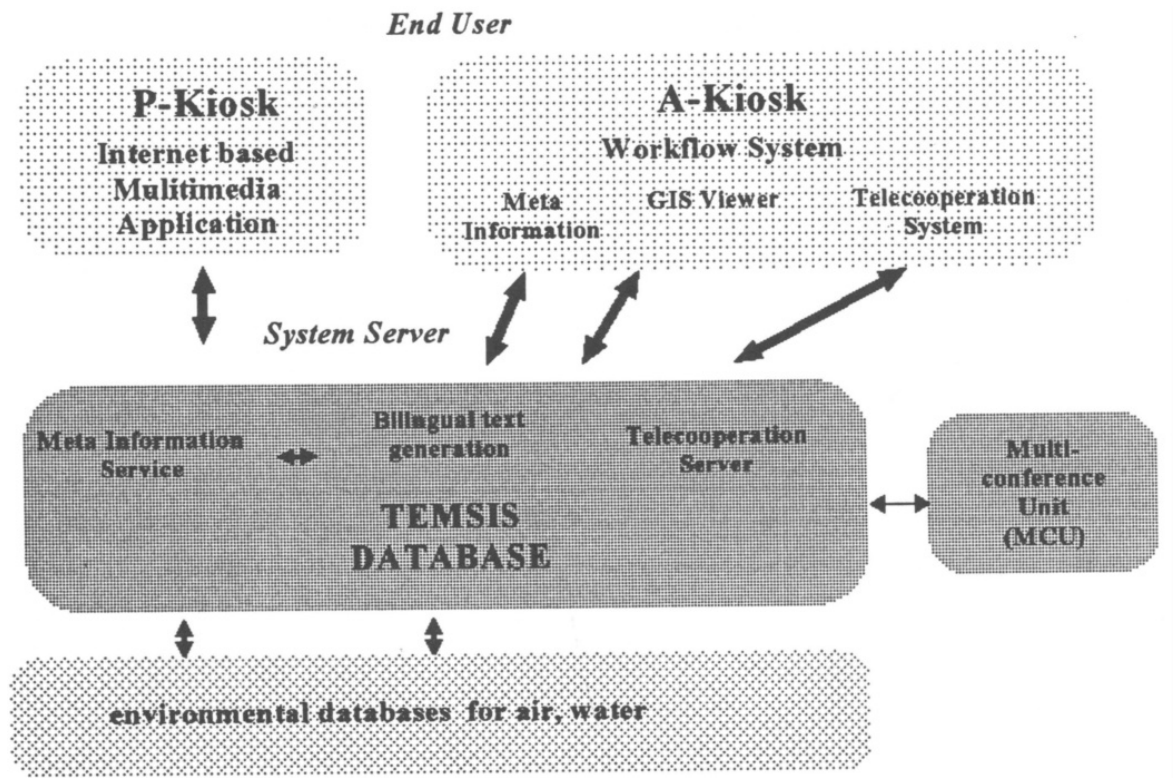

Figure 1: Overall System Structure

Additionally we will integrate heterogeneous data extracted from geographical information systems (GIS) for land use an land use planning. To manage this problems here and as mentioned in chapter 4 . It will be necessary to implement a metadata server in front of each database system. Thus it will also be ensured that every data provider keeps his authority 


\section{CONCLUSION AND PROSPECTS}

The TEMSIS project is dealing with 2 different aspects of managing environmental data. One is the monitoring of data for experts and afterwards the transfer into the public. The experts uses special tools like Graphical Information Systems (GIS) and distributed data bases connected with a Meta information service. To make the results public the World Wide Web is an ideal medium to reach everyone. The second aspect is the possibility of cooperation between the experts using the Telecooperation platform. By this way experts at different locations can work together to create common statements. The public user may be involved in the decision process using a discussion forum which uses the interactivity of the web.

With this configuration you have 2 different platforms to support, the expert platform based on a PC with special tools and the public platform based on the web. The transfer from one to the other platform is a problem. Future activities are more and more relating to web platforms because this is unique for all operating systems. But before some problems have to be solved. One problem is the security. The web is very unsecured and therefore not good for confidential information. If the second problem, the speed, will be solved, there will be more interactivity and Telecooperation systems can be used successfully in the web.

\section{REFERENCES}

Burgard, J.; Schweitzer, J. (1993) CLE: Cooperative Learning in a Distributed Multimedia Environment. Proceedings of the IFIP TC3 Third Teleteaching Conference, Tele Teaching 93, Trondheim, Norway.

Denzer, R. ; Güttler,R. (1995) An Overview on Integration Problems in Environmental Information Systems. ICCI, Univ. of Trent, Canada.

Schimak, H. Humer, R. Denzer, E. Knappitsch (1994) The Ozone Network for Austria - Technical Concept of a Distributed Environmental Information System. in: L. M. Hiltz et al. (eds.), Informatik für den Umweltschutz, 8. Symposium, Metropolis, Hamburg, pp. 89-96.

Schmidt T., J. Schweitzer, M. Weber (1994) A Framework for Synchronous Telecooperation, Proceedings of the Intenational Workshop an Advanced Communications and High Speed Networks, IWACA, Heidelberg

Schweitzer, J., Schneider, G., Maus, H., Dietel, C., Scheller-Houy, A (1996) Concepts for a flexibilisation of workflow management systems with respect to task adaptable solutions, Proceedings AAAI-96 Workshop „AI in Business", Portland, Oregon. 